Insight Microbiology 1 (2): 20-30, 2011

ISSN 2041-0387

(C) 2011 Insight Knowledge, UK

\title{
The Effect of Mycorrhizae Inoculated Maize Root Exudates in Alleviation of Chromium Toxicity in Chromium Polluted Environments
}

\author{
M. Gomathy, K.G. Sabarinathan, M. Thangaraju, K.S. Subramanian, T. Sivashankari Devi and K. Ananthi \\ Tamil Nadu Agricultural University, Coimbatore-3, Tamil Nadu, India
}

\begin{abstract}
Background: Tanneries are one of the most polluting industries in India. The toxic effect of chromium is primarily dependent on the metal speciation which determines its uptake, translocation and accumulation. Results: Initial pot culture trial revealed that the lower accumulation of chromium in the mycorrhizal inoculated shoots and higher accumulation in the roots of maize crop. Microtome analysis also revealed the accumulation of chromium in the root cortex of maize. So the study is further extended to study the root exudates of mycorrhizae inoculated maize plant for the identification of different compounds responsible for chromium stress tolerance. The effect of mycorrhizal root exudates on chromium sequestration is studied. Samples are subjected to thin layer chromatography, High Performance Liquid Chromatography (HPLC) and Gas Chromatography Mass Spectrometry (GC-MS). GC-MS analysis of the separated fractions enables identification of various organic acids including fatty acids, phenols etc. Conclusions: Higher concentration of chromium resulted in increased organic acid excretion from the mycorrhizal roots. Non mycorrhizal samples showed less concentration of root exudates. So inoculation of mycorrhizae is the ideal one to bioremediate the chromium contaminated areas.
\end{abstract}

Key words: Arbuscular mycorrhizal fungi, Zea mays, root exudates, heavy metals, organic acids, chromium, HPLC, microtome

\section{INTRODUCTION}

Elevated concentration of heavy metals in the environment, cause a potential health hazard in the long term. Contaminant metals accumulate in plant tissues and animal system. Plants take up heavy metals from their surroundings through a number of different plasma membrane localized transporters. Inside the plant system toxicity of heavy metals is manifested by an array of physiological and metabolic disturbances if metal detoxification processes are delayed or not efficient (Mishra and Dubey, 2006). Chromium is one of the heavy metal which exists in two important oxide states: trivalent (Cr III) and hexavalent (Cr VI) in agricultural soils. Chromium is extensively used in the industries like textile, steel, leather etc (Dixit et al., 2002). This chromium causes severe oxidative damage to plant cells. It affect the growth, water balance, pigment content etc (Bonet et al., 1991). Cr stress is one of the important factors that affect photosynthesis in terms of $\mathrm{CO}_{2}$ fixation, electron transport, photophosphorylation and enzyme activities (Clijsters and Assche, 1985). Pollutants could cause injury to the plant leaves, stomatal damage, premature senescence, decreased photosynthetic activity and reduced growth (Seyyednejad et al., 2011). In many plants, increase in DNA content has been observed with the increase in $\mathrm{Cr}$ concentration (Bishnoi et al., 1993). This $\mathrm{Cr}$ induces oxidative stress in the plants and as a result Reactive Oxygen Species (ROS) are produced as intermediate products in a number of metabolic reactions in various cellular organelles (Panda, 2002). Arbuscular Mycorrhizal (AM) fungi are soil microorganisms which can alleviate chromium toxicity and supports greater plant growth in chromium contaminated soils (Davis et al., 2001). During this environmental stress condition roots release greater quantities of organic compounds in the rhizosphere (Whipps, 1990) which relieve the external stress. The releasing of organic acids from the root is a general mechanism for solubilizing metals and act as an detoxification mechanism in acid soils (Jones and Darrah, 1994). AM fungi excrete organic acids such as citric, malic and oxalic acids into the rhizosphere (Landeweert et al., 2001). Root exudates are the first plant signals that AM fungi perceive and thought to play an important role in establishment of AM symbiosis. So an experiment was conducted to know the effect of root exudates on the chromium sequestration in the chromium contaminated soils. The root exudates of AM contain many organic

Corresponding Author: Dr. M. Gomathy, KTC Nagar, Tirunelveli District, Tamil Nadu, India Tel: 91(11) 9944627322 
compounds such as amino compounds, organic acids, fatty acids, sterols, flavones etc which helped in the heavy metal sequestration.

\section{MATERIALS AND METHODS}

Preliminarily pot culture study was carried out in an Alfisol (Red sandy loam soil) at the Department of Agricultural Microbiology, Tamil Nadu Agricultural University, Coimbatore, India. The soil was analyzed for its chromium content $(5 \mathrm{ppm})$ and evaluate for its indigenous soil mycorrhizal population $\left(10\right.$ spores $\mathrm{g}^{-1}$ of soil). The experimental soil was spiked with chromium at the rate of $0,500,1000,1500$ and $2000 \mathrm{mg} \mathrm{kg}^{-1}$ of soil in the form of potassium dichromate. After the establishment of functional symbiosis (45 Days after sowing) root and shoot samples were analyzed in AAS (Perkin Elmer 3100 EDS) to detect the accumulation of chromium.

Microtome method: Roots were collected from three plants at 60 days after treatment with $\mathrm{Cr}$ as representative samples for microtoming and staining. Thin sections were taken and the sections showing distinct changes were photomicrographed using Olympus microscope (Zeiss).

Collection of root exudates: Root exudates were collected according to the procedure of Lee and Gaskins (1982). The procedure was modified by spiking the acid washed sand with different concentrations $(0,500,1000,1500$ and $2000 \mathrm{mg} \mathrm{kg}^{-1}$ of sand) of chromium and then 15 days old maize seedling was taken, rinsed with sterile water repeatedly and the seedling was planted aseptically and inoculated with the AM fungus Glomus intraradices. Uninoculated control with different concentrations of chromium was also maintained. After 4 weeks of planting the seedlings were removed carefully and the exudates were extracted from the sand with acetonitrile. Then the extract was filtered, condensed and stored for further analysis. Contamination checks were done after 15 days during plant growth by serial dilution and plating technique on nutrient agar, Rose Bengal agar and Ken knights agar media to check the bacteria, fungi and actinomycetes population. No contamination was observed. The condensed extract was then purified using column chromatography.

Column chromatography: Silica gel for column chromatography (40 mesh (60 g)) was made into a slurry in acetonitrile solvent. The tube was $30 \mathrm{~cm}$ in length $1 \mathrm{~cm}$ diameter. The bottom of the column was plugged with glass wool. The column was kept upright. Slurry of silica gel and acetonitrile was made. A small volume of acetonitrile was poured in to the column to avoid trapping of any air bubbles in the plug and immediately the column was filled with the slurry. The top portion was carefully stirred gently prior to pouring additional slurry into the column. The silica gel settled down to the height by gravitational force. Column can be increased by adding further amount of silica gel slurry. The column was equilibrated thoroughly by passing the acetonitrile through the column. Then the root exudate was poured into the acetonitrile silica gel column. The effluent is collected in intervals in tubes and then it was dried in vacuum and further purified by preparative thin layer chromatography.

Preparative thin layer chromatography: The vacuum dried sample was mixed with one $\mathrm{mL}$ of acetonitrile and this sample was used for thin layer chromatography. Dry clean glass plates $20 \times 20 \mathrm{~cm}$ were taken and kept over plain surface. Silica gel was taken with that distilled water was added and it was prepared like slurry. The slurry was stirred constantly for 1-2 min. The slurry was coated uniformly over the glass plates at a thickness of $0.25 \mathrm{~mm}$. Then the plates were kept in the oven at $100-120^{\circ} \mathrm{C}$ for $1-2 \mathrm{~h}$ to remove the moisture and to activate the adsorbent on the plate. The dried plates were taken out of the oven. The $2.5 \mathrm{~cm}$ distance was left from one end of the glass plate. The sample was applied by means of micropipetter as small spots. All spots were placed at equal distance from one end of the plate. The solvent acetonitrile was poured into the tank to a depth of $1.5 \mathrm{~cm}$. Thin layer plate was kept in to the tank vertically. Then the top of the plate was covered with a plate. The separation of the compounds occurred as the solvent moved upward. When the solvent reached the top of the plate the plate was removed from the tank and kept for drying. The compounds were separated as a series of bands. Then the area was scrapped off where the compound get separated and kept in refrigerator for further analysis.

\section{HPLC}

Apparatus: Root exudates estimation was performed using Shimadzu LC-8A model preparative liquid chromatography equipped with photodiode array detectors and reverse phase $\mathrm{C} 18$ column. The maxplot spectrum was recorded on photodiode array detector. 
The scrapped sample obtained from TLC was mixed with acetonitrile solvent. The silica gel was removed by centrifugation at $15,000 \mathrm{rpm}$ for $10 \mathrm{~min}$. Then it was filtered through $0.2 \mu \mathrm{m}$ Millipore membrane filter. The filtered solution was used for HPLC analysis (Shimadzu PDA C18 column).

HPLC grade acetonitrile solvent and milique water was added with $0.1 \%$ Triflurotertrazolium were used as a mobile phase. A sample injection volume of $25 \mu \mathrm{L}$ was used. The separation of root exudates compounds were achieved using acetonitrile water $(60: 40) \mathrm{mL} \mathrm{min}^{-1}$ and peaks monitored at $240 \mathrm{~nm}$.

GC-MS: Root exudates collected from HPLC were analyzed by GC-MS (model-Clarus 500 MS, Perkin Elmer). Separation of biochemical constituents in root exudates of maize treated with chromium was carried out on DB-1 column ( $30 \mathrm{~m}$ length $\times 0.25 \mathrm{~mm} \mathrm{ID}$ and $0.5 \mu \mathrm{m}$ thickness). The carrier gas was Helium, at a flow rate of $\mathrm{mL} \mathrm{min}^{-1}$. Temperature settings were as follows, $100^{\circ} \mathrm{C} \times 1 \mathrm{~min}$ to 250 to $5^{\circ} \mathrm{C} / \mathrm{min}-250 \times 10 \mathrm{~min}$ with injector and transfer line temperatures of 250 and $280^{\circ} \mathrm{C}$, respectively. The mass spectrometer was used to detect the ions generated by electron ionization $(70 \mathrm{eV})$ at the ion source temperature of $180^{\circ} \mathrm{C}$, with a mass range from 50 to $320 \mathrm{D}$. The eluted organic acids were detected with quadropole MS. The compounds were identified by matching with the libraries WILEY and NIST.

\section{RESULTS}

Cr accumulation: The data on chromium concentration in shoots and roots indicated that incremental levels of chromium spiking linearly increased the chromium content regardless of mycorrhizal $\left(\mathrm{M}^{+}\right)$or non- mycorrhizal $(\mathrm{M})$ conditions. However, such increase in the chromium was more pronounced in mycorrhizal colonized roots $\left(\mathrm{M}^{+}\right)$than shoots and the reverse was true for non-mycorrhizal (M) plants (Table 1).

Root exudates analysis: Mycorrhizal and non mycorrhizal root exudate samples when subjected to HPLC analysis. Mycorrhizal samples with varying concentrations of chromium showed peaks of organic acids at different retention time but no organic acid peaks were detected in non mycorrhizal samples.

The root exudates of mycorrhizal and non mycorrhizal samples eluted as peaks at different intervals were collected using fraction collector and then further these samples were analyzed in GC-MS to identify the compounds present in the root exudates of mycorrhizal and non mycorrhizal samples (Table 2).

All the five treatments and control showed considerable amount of fatty acids and organic acids. In control, only fatty acids were observed like lauric, myristic, capric palmitic and penta decanoic acids (Fig. 1a). But in treatments, apart from fatty acids, organic acids and phenols were observed. In control i.e., in 0 ppm without mycorrhizal inoculum less number of compounds were detected compared to inoculated ones (Fig. 1b). The compounds identified were lauric, myristic capric, stearic, palmitic, penta decanoic, pelargonic, methyl octadecanoate and methyl myristate. In $500 \mathrm{ppm}$ of chromium concentration fatty acids and other organic acids like acetic, benzoic were expressed (Fig. 2a).

Figure $2 \mathrm{~b}$ shows the GC-MS chromatogram of $1000 \mathrm{ppm}$ of chromium treated maize plant root exudates. GC-MS enabled the separation of compounds of different molecular mass. M (134) i.e., Malic acid, M (129) i.e., Carboxylic acid, M (180) Acetyl salicylic acid, M(242) i.e., Acetic acid, etc. In this treatment proline was expressed in GC-MS analysis.

Figure 2c shows the GC-MS chromatogram of $1500 \mathrm{ppm}$ of chromium treated maize plant root exudates. Twenty individual compounds were identified in the root exudates of maize crop grown in $1500 \mathrm{ppm}$ concentration of chromium. Some of them identified were malic acid, uric acid, succinic acid, Butanoic acid, Carbanoic acid, Glutamic acid, Sanoic acid, stearic acid, etc.

Figure $2 \mathrm{~d}$ shows the GC-MS chromatogram of $2000 \mathrm{ppm}$ of chromium treated maize plant root exudates. Tridecanoic acid, acetic, carboxylic, malic, ascorbic, margaric, propionic, sanoic, salicylic, succinic and phenylalanine were the compounds identified.

Table 1: Concentrations of $\mathrm{Cr}$ in shoot and root tissues of maize plants inoculated without and with Glomus intraradices

\begin{tabular}{|c|c|c|c|c|}
\hline \multirow[b]{3}{*}{$\begin{array}{l}\text { Cr concentration } \\
\left(\mathrm{mg} \mathrm{kg}^{-1}\right)\end{array}$} & \multicolumn{4}{|c|}{ Chromium content $\left(\mathrm{mg} \mathrm{kg}^{-1}\right)$} \\
\hline & \multicolumn{2}{|l|}{$\mathrm{M}^{+}$} & \multicolumn{2}{|l|}{$\mathrm{M}^{-}$} \\
\hline & Roots & Shoots & Roots & Shoots \\
\hline 0 & 1.8 & 1.4 & 5.8 & 3.4 \\
\hline 500 & 335.8 & 81.4 & 81.6 & 225.0 \\
\hline 1000 & 709.8 & 99.4 & 125.6 & 657.0 \\
\hline 1500 & 783.8 & 155.4 & 499.6 & 733.0 \\
\hline 2000 & 1001.8 & 207.4 & 573.6 & 911.0 \\
\hline $\mathrm{Cr}$ & $* * *$ & & $* * *$ & \\
\hline VAM & $* *$ & & $* * *$ & \\
\hline $\mathrm{Cr} \times \mathrm{VAM}$ & **** & & 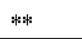 & \\
\hline
\end{tabular}

Values are the means of four replicate samples. $\mathrm{M}^{+}$: Mycorrhizae (inoculated), $\mathrm{M}^{-}$: My pcrhizae (uninoculated). ** Singnificant at $\mathrm{p}<0.01$ 


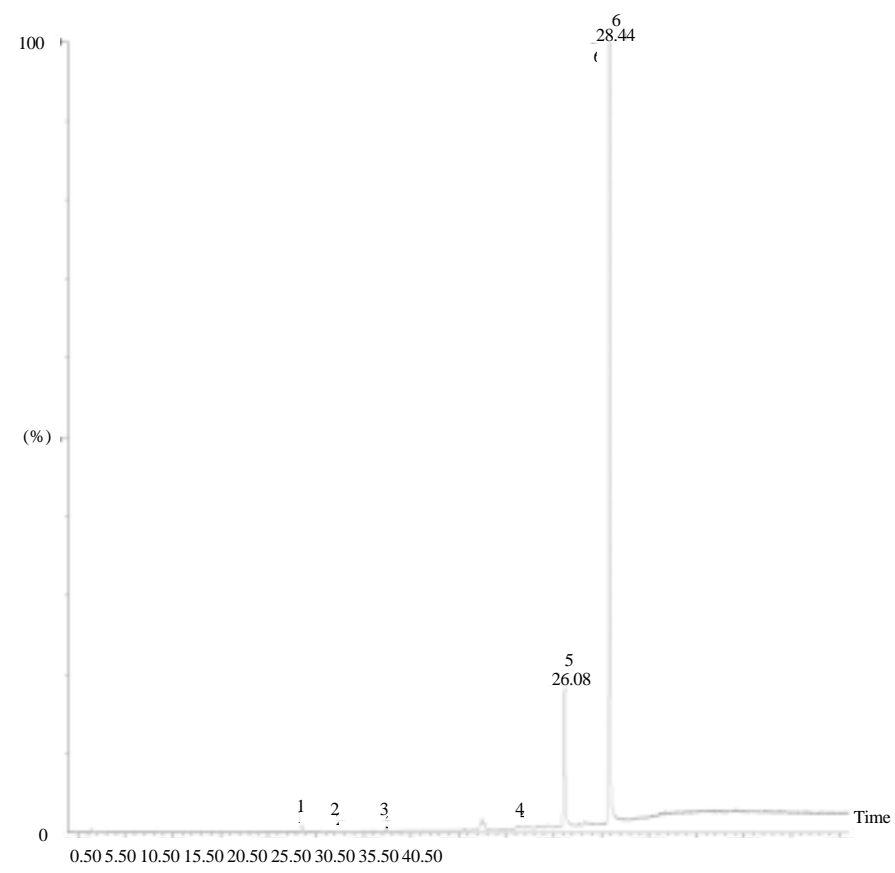

Fig. 1a: GC-MS analysis of root exudates extracted from inoculated maize crop treated with 0 ppm Cr. 1:Lauric acid, 2: Capric acid, 3: Myristic acid, 4: Stearic acid, 5: Oleic acid, 6: Penta decanoic acid

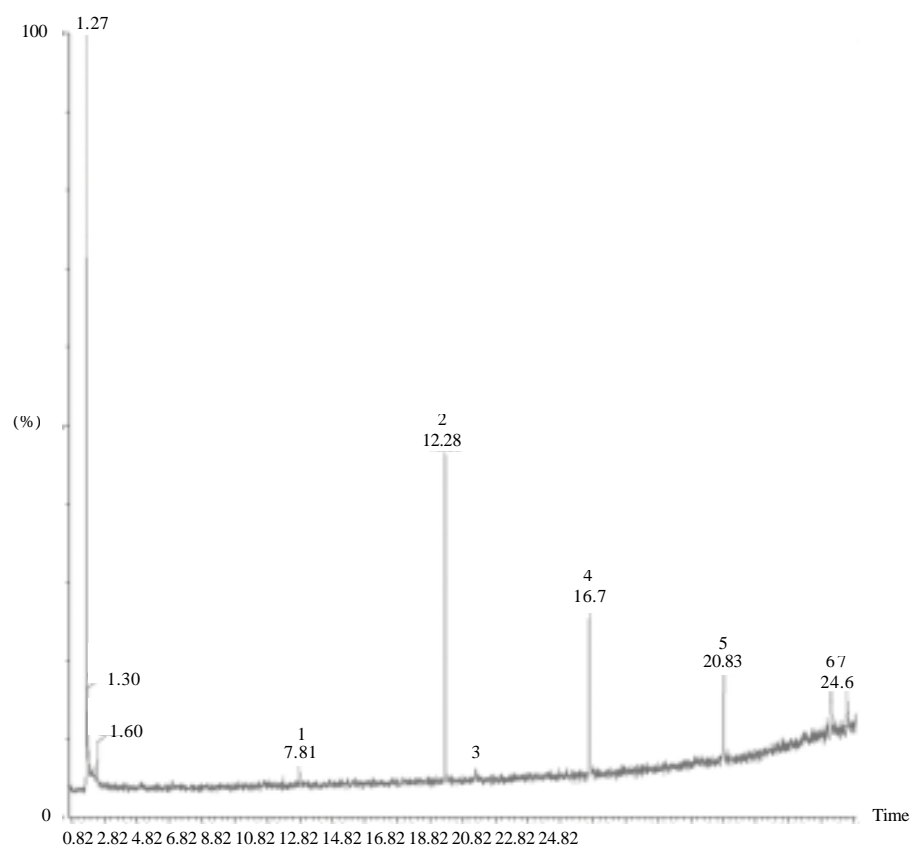

Fig. 1b: GC-MS analysis of root exudates extracted from G. intraradices inoculated maize crop treated with $0 \mathrm{ppm} \mathrm{Cr}$. 1: Methly 10 bromodecanote, 2: Lauric aicd, 3: Capric acid, 4: Myristic acid, 5: Palmitic acid, 6: Methyl octadecanoate and 7: Stearic acid 


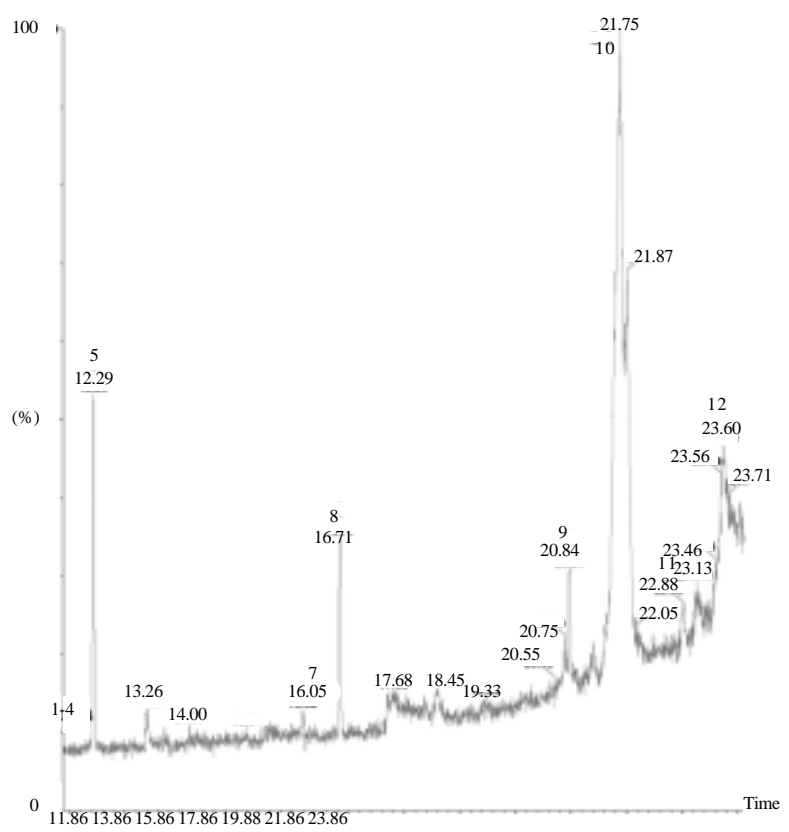

Fig. 2a: GC-MS analysis of root exudates extracted from $G$. intraradices inoculated maize crop treated with $500 \mathrm{ppm}$ Cr. 1: Pclargonic acid, 2: Methyl 10 bromokedccanoate, 3: Acctic acid, 4: Benzoic acid, 5: Lauric acid, 6: Methyl 13 methyltertradecanoate, 7: Methyleterdccanoate, 8: Tridccanoic acid, 9: Palmitic acid, 10: Pthalic acid, 11: Oleic acid and 12: Stearic acid

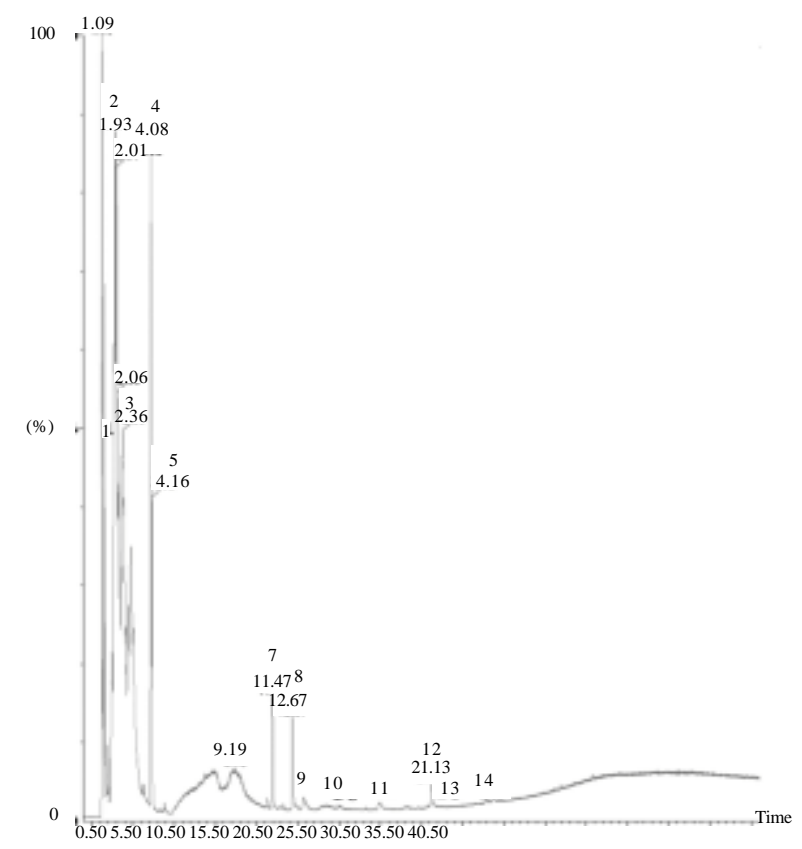

Fig. 2b: GC-MS analysis of root exudates extracted from $G$. intraradices inoculated maize crop treated with $1000 \mathrm{ppm}$ Cr. 1: Malic acid, 2: Proline, 3: Carboxulic acid, 4: Nitrophenol, 5: Butanoic acid, 6: Benzoic acid, 7: Uric acid, 8: Lauric acid, 9: Capric acid, 10: Methyl tetradecanoate, 11: Myristic acid, 12: Ascorbic acid and 13: Margaric acid 


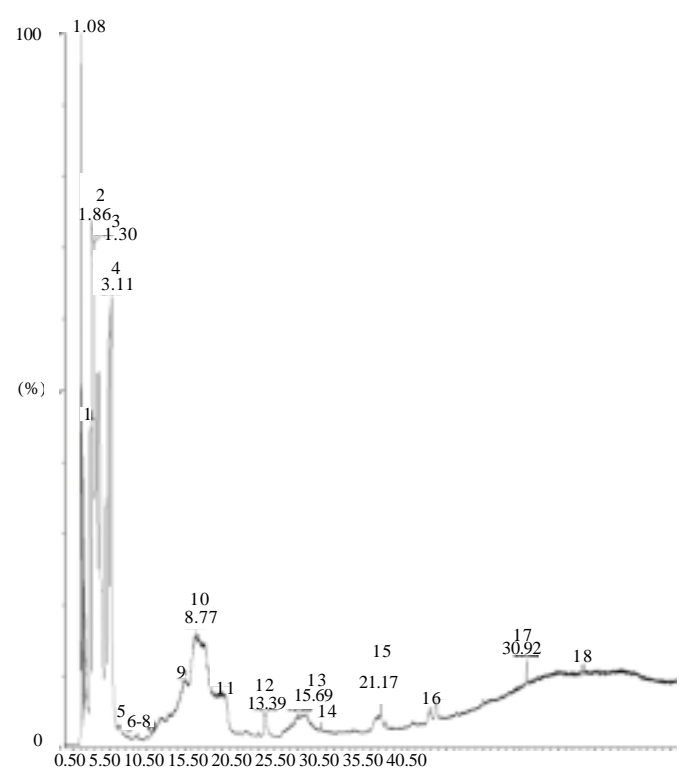

Fig. 2c: GC-MS analysis of root exudates extracted from $G$. intraradices inoculated maize crop treated with $1500 \mathrm{ppm}$ Cr. 1: Malic acid, 2: Proline, 3: Malonic acid, 4: 3-Butyn-2-amine, 5: Vinyl cyclopentane, 6: Carbonic acid, 7: Cyclopropane carboxylic acid, 8: Butanoic acid, 9: Succinic acid, 10: Phynylalanine, 11: Salicylic acid, 12: Capric acid, 13: Glutamic acid, 14: Pidolic acid, 15: Propionic acid, 16: Margaric acid, 17: Methyl malonic acid and 18: Sanoic acid

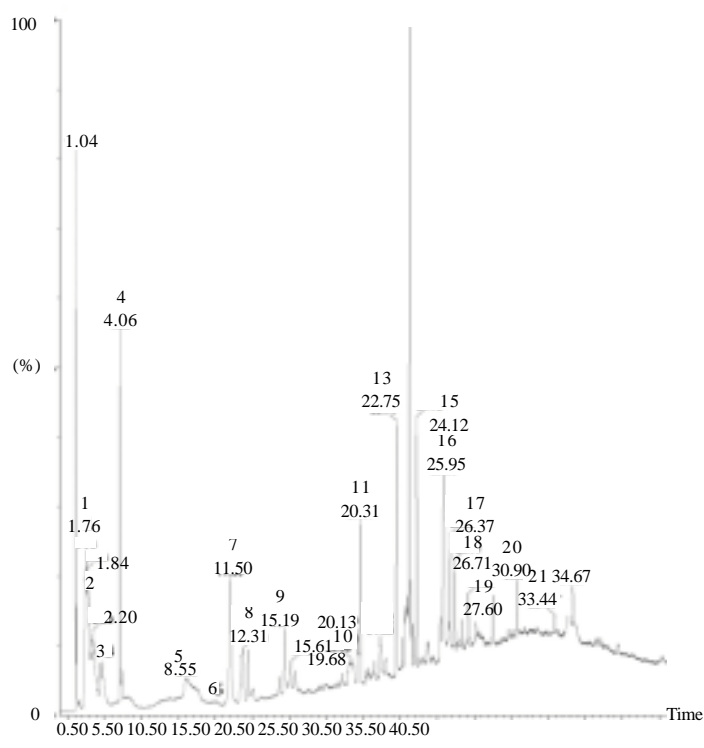

Fig. 2d: GC-MS analysis of root exudates extracted from $G$. intraradices inoculated maize crop treated with $2000 \mathrm{ppm}$ Cr. 1: Malic acid, 2: Malonic acid, 3: Acetic acid, 4: Nitrophenol, 5: Phenylalanine, 6: Salicylic acid, 7: Octadecanoic acid, 8: Cyclotridecane, 9: Methyl tetradecanoate, 10: Palmitic acid, 11: Pentadecanoic acid, 12: Ascorbic acid, 13: Propionic acid, 14: Oleic acid, 15: Hexanoic acid, 16: Arachidonic acid, 17: 5, 8, 11, 14, Eicosatetraenoic acid 18: Ethyllinoleate, 19: Docosanedioic acid, 20: Methyl stearate and 21: Sanoic acid 
Insight Microbiology 1 (2): 20-30, 2011

Table 2: Volatile compounds exuded from the G. intraradices inoculated roots of maize crop under control and different concentrations of chromium

\begin{tabular}{|c|c|c|c|c|c|c|}
\hline Compounds & $0 \mathrm{ppm}$ & $500 \mathrm{ppm}$ & $1000 \mathrm{ppm}$ & $1500 \mathrm{ppm}$ & $2000 \mathrm{ppm}$ & Control \\
\hline Lauric acid & + & + & + & - & - & + \\
\hline Myristic acid & + & - & + & - & - & + \\
\hline Capric acid & + & - & + & - & - & + \\
\hline Stearic acid & + & + & - & - & - & + \\
\hline Oleic acid & & + & - & - & + & + \\
\hline Penta decanoic acid & + & - & - & - & + & + \\
\hline Palmitic acid & + & + & - & - & + & \\
\hline Pelargonic acid & + & + & - & - & - & - \\
\hline Tridecanoic acid & - & + & - & - & - & - \\
\hline Penta decanoic acid & - & - & - & - & + & - \\
\hline Hexanoic acid & - & - & - & - & + & - \\
\hline Pthalic acid & - & + & - & - & - & - \\
\hline Methyl tetradecanoate & - & + & + & - & + & - \\
\hline Methyl 13 methyl tetradecanoate & - & + & - & - & - & - \\
\hline Methyl octadeconate & + & - & - & - & - & - \\
\hline Methyl 10 bromodecanoate & - & + & - & - & - & - \\
\hline Methyl malonic acid & - & - & - & + & + & - \\
\hline Methyl stearate & - & - & - & - & + & - \\
\hline Arachidonic acid & - & - & - & - & + & - \\
\hline Acetic acid & - & + & - & - & + & - \\
\hline Benzoic acid & - & + & + & - & - & - \\
\hline Carboxylic acid & - & & + & - & - & - \\
\hline Malic acid & - & - & + & + & + & - \\
\hline Uric acid & - & - & + & - & - & - \\
\hline Ascorbic acid & - & - & + & - & + & - \\
\hline Margaric acid & - & - & + & + & - & - \\
\hline Propionic acid & - & - & - & + & + & - \\
\hline Butanoic acid & - & - & + & + & - & - \\
\hline Glutamic acid & - & - & - & + & - & - \\
\hline Pidolic acid & - & - & - & + & - & - \\
\hline Sanoic acid & - & - & - & + & + & - \\
\hline Salicylic acid & - & - & - & + & + & - \\
\hline Succinic acid & - & - & - & + & - & - \\
\hline Linolelaidic acid & - & + & - & - & - & - \\
\hline Carbonic acid & - & - & - & + & - & - \\
\hline Docosanedioic acid & - & - & - & - & + & - \\
\hline Methyl malonic acid & - & - & - & + & - & - \\
\hline Cyclopropane carboxylic acid & - & - & - & + & - & - \\
\hline Nitrophenol & - & - & + & - & + & - \\
\hline Proline & - & - & + & + & - & - \\
\hline Phenylalanine & - & - & - & + & - & - \\
\hline Ethyllinoleate & - & - & - & - & + & - \\
\hline 3-Butyn-2-amine & - & - & - & + & - & - \\
\hline Vinyl cyclopentane & - & - & - & + & - & - \\
\hline Cyclotridecane prop & - & - & - & - & + & - \\
\hline 5,8,11,14 Eicosattraenoic acid & - & - & - & - & + & - \\
\hline
\end{tabular}

+: Present,

\section{DISCUSSION}

Mycorrhizal plants accumulated chromium more in roots than shoots indicating retention of chromium within roots while preventing it to the aerial parts. It is understandable that mycorrhizal structures associated with roots luxuriantly take up chromium and retains with in roots. This process facilitates phytoextraction mechanism which is one of the potential factors related to the phytoremediation of heavy metals. As a consequence of rapid removal of chromium by mycorrhizal plants the inoculated soil had $50 \%$ lower concentration of chromium than their counterpart non inoculated soil. $\mathrm{Zn}$ and $\mathrm{Cu}$ elements were found in leaf samples of pinus eldarica when they were irrigated with effluent (Salehi and Tabari, 2008). Davis et al. 2001 reported that mycorrhizae plants have greater ability to absorb and accumulate chromium and assist in phytoextraction mechanism. The mechanism behind the prevention of heavy metal entry in to the shoot portion of the plant was studied through the metal binding properties of root exudates from maize plant. Root exudates are important agents which form complexes with heavy metals and affect their redox potential (Caltado et al., 1988). Root exudates contain organic acids that form complexes with chromium compounds making them unavailable for plant uptake.

The present study also revealed that $\mathrm{Cr}$ was accumulated in the cortex region of cells where hyphae 
and vesicles present. This accumulation of $\mathrm{Cr}$ in cortical cells was a detoxification mechanism attributed by the mycorrhizae which reduced the availability of $\mathrm{Cr}$ in the soil and in the aerial parts of the plant. Similarly, Vazqyez et al. (1992) also observed that at low Cd concentration, Cd get accumulated in the vacuole of Thlaspi species. Ade-Ademilua and Obalola (2008) found that the frequency and size of the epidermal cells and stomata of the leaves of Celosia argentea were greatly modified due to the cement dust pollution which contains iron, calcium, magnesium, aluminium, silicon and sulphur. Doss and Bagayaraj (1990) observed a striking increase in the thickness of leaf, size of veins and plastid number in the leaves of mycorrhizal plants of pearl millet.

Salicylic acid expressed in the higher concentration of chromium was not expressed in lower concentration and in control. So the non mycorrhizal plants did not secrete the salicylic acid. Salicylic acid was expressed both in 1500 and $2000 \mathrm{ppm}$ of chromium treated root exudates. It is an important signaling agent involved in establishing local and systemic resistance. Salicylic acid level increased when there is a stress which induced the stress related proteins and initiate development of systemic acquired resistance (Alvrez, 2000). The salicylic acid expression in these treatments appeared to regulate the balance between pro and anti death functions during hypersensitive response. It is reported to play a role in plant disease resistance and hypersensitive cell death and also implicated in hardening responses to abiotic stresses (Matewally et al., 2003). These mycorrhizae inoculated plants secreted more number of organic acids when compared to control. Due to a high chromium stress the mycorrhizal plants were induced to secrete salicylic acid to over come the stress whereas, the uninoculated plants did not show any important compounds. Matewally et al. (2003) reported that one mechanism is avoidance of damage and includes any mechanism of cadmium binding resulting in lowered plasmatic free cadmium. Rea et al. (1998) reported that salicylic acid could enhance repair processes. Salicylic acid stimulated expression of certain $\mathrm{ABC}$ transporters. These transporters were implicated in vacuolar sequestering of the products of cadmium. Salicylic acid provided protection against abiotic stress such as heat stress in mustard (Dat et al., 1998) or chilling damage in maize (Janda et al., 1999). In this study salicylic acid helped the plant to overcome the chromium stress.

Ascorbic acid was also expressed in the higher concentration of chromium treated root exudates of maize plant. Ascorbic acid increases the plant tolerance to reactive oxygen species by participation in the detoxification of reactive oxygen species in plant cells (Noctor and Foyer, 1998). Due to the chromium treatment oxidative stress was observed and reactive oxygen species were formed. Ascorbic acid was involved in the detoxification of reactive oxygen species in plants (Ozturk et al., 2003). So this ascorbic acid which was expressed in 1000 and $2000 \mathrm{ppm}$ of chromium treated root exudates might have helped the maize plant overcome the toxicity stress created by chromium. Malic acid was also found to inhibit the blocking of the root cell plasma membrane and helped the plant to grow without any damage under $\mathrm{Al}$ stress.

Organic acids excreted from roots have heavy meal tolerance or avoidance mechanism (Delhaize and Ryan, 1995). In the present study also increasing chromium concentration resulted in increased amount of organic acid secretion by the VAM fungi. The ability of the ericoid mycorrhizal fungus Oideidendron maius to mobilize zinc compounds from metal contaminated sites through the secretion of organic acids. Shahandeh and Hossner (2000) reported a high increase in chromium uptake which was aided by the secretion of organic acids. Similar results were obtained by James and Bartlett, 1983 who reported that organic acids like citric, aspartic and oxalic acids increased the solubility for a longer period of time which in turn available easily to the plants. Chaffai et al. (2006) analyzed the organic acid exudation from maize and revealed that citrate exudation was not affected by copper or cadmium metals. Citric and oxalic acids avoid phytotoxicity and helps in the extending metal bio availability period for plant uptake (Turgut et al., 2004). Similarly, Williams and Nascimento (2006) reported that aromatic low molecular weight organic acids such as vanillic and gallic acids were the least effective in desorbing the metals from soil. AM fungi secrete several organic acids to remove metals form soil solution by interaction between the heavy metal and organic acids (Landeweert et al., 2001).

Malic and citric acids played a major role in heavy metal tolerance in sunflower (Harmens et al., 1993). Organic acid such as malic acid was suggested to play a key role in sequestering $\mathrm{Zn}$ from cytoplasm to vacuoles (Mathys, 1997). In this study malic acid was expressed in the root exudates of 1000,1500 and $2000 \mathrm{ppm}$ of chromium treated maize plants. They might have helped the plant to detoxify chromium toxicity by sequestering chromium in to the vacuole as plant vacuoles are a major deposit for organic acids (Matile and Wiemken, 1976) and involved in detoxification of metals (Boominathan and Doran, 2003). Mycorrhizal species excrete different kinds of organic acids for different kinds of heavy metals. This organic acid also helped the fungus to immobilize the copper on to their external hyphae and reduced the free copper concentration (Meharg, 2003). Contradictorily, 
Srivastava et al. (1999) reported that organic acids and amino acids found to be less effective in mobilizing chromium.

In general many fatty acids were observed in the root exudates of chromium treated plants. They are mainly involved in the reduction of free radicals in lipid peroxidation (Girotti, 2001). Fatty acids observed are more at increasing concentrations of chromium which might be showing a defense mechanism to counteract oxidative damage. Einicker-Lamas et al. (1996) reported increase in lipid content due to increase in cadmium concentration related to detoxification mechanism. Changes in the fatty acid levels by chromium treatment was a defense or repairing mechanism to reduce the cellular damage and stress caused by the hexavalent chromium (Rocchetta et al., 2003). In this study, soil treated with 1000,1500 and $2000 \mathrm{ppm}$ of chromium concentrations were found to elute fatty acids and organic acids like benzoic acid, acetic acid, propanoic acid, carboxylic acids which sequester the heavy metals effectively. Increase in chromium accumulation from chromium treated maize plants in the presence of increasing concentrations of organic acids has been observed (Srivastava et al., 1999). Mycorrhizas and organic acids have been reported to play an important role in chromium contaminated soils (Davies et al., 2001). Ahonen-Jonnarth et al. (2000) reported that oxalic acid was excreted in the rhizosphere of mycorrhizal plants and not in the non mycorrhizal plants. AM fungi increased the oxalic acid secretion at increasing concentrations of aluminium and copper.

Phenolic acids were also observed in the root exudates of plants which were treated with 500,1500 and $2000 \mathrm{ppm}$ of chromium concentration. Phenolics have the ability to eliminate radical species and function as metal chelators which prevent fenton reactions. Phenolics are powerful antioxidants than the hydroxy derivatives of benzoic acids (Rice-Evans et al., 1996). Zancani and Nagy (2000) reported that in the presence of phenols and ascorbate, peroxidase could act efficiently in $\mathrm{H}_{2} \mathrm{O}_{2}$ scavenging in plant vacuoles. So in this study, phenols such as benzoic acids, copper ferulic and para hydroxybenzoic acids were increased three folds. So these phenols might have acted as scavengers for the reactive oxygen species.

Amino acid binds the heavy metals (Reilly, 1972). Amino acids are excreted in higher amounts when there is higher metal stress and it is more significant in metal accommodation (Mazen, 2004). Amino acids were reported to play a major role in metal chelation. In this study also amino acid like proline, phenylalanine were expressed in higher concentrations of chromium treated maize plant root exudates. Proline content increased proportionately with increasing metal concentration of $\mathrm{Cd}, \mathrm{Co}, \mathrm{Zn}$ and $\mathrm{Pb}$ in Lamna minor plant. These amino acids and peptides bind metals in the cytosol and sequester them in the vacuole.

Many plants accumulated higher concentrations of proline when they were treated with heavy metal (Schat et al., 1997). Proline protects the plant from heavy metal toxicity by inhibiting the metal induced lipid peroxidation (Seel et al., 1992). This amino acid plays a major role in protecting the plant against metal toxicity by providing water balance which is often disturbed by heavy metal (Schat et al., 1997). It also helped in the scavenging hydroxyl radicals (Smirnoff and Cumbes, 1989), chelating heavy metals in the cytoplasm (Farago and Mullen, 1979). This proline also protects the plasma membrane of the plant from copper toxicity. So the proline accumulated in the high concentrations of chromium treated root exudates might have played a major role in protecting the plants from chromium toxicity. It might be that proline reduced the harmful radicals and sequestered the heavy metals inside the cell. Amino acids such as histidine are potential ligands for heavy metals and can detoxify them (Clemens, 2001).

\section{CONCLUSION}

Under stress conditions AM fungi was induced to produce root exudates which contains organic acids. This organic acids produced by AM fungi may chelate the toxic metals which might have resulted in the formation of metallo organic molecules and this makes the bioavailability of chromium for a longer period of time. Plants absorb this chromium and its translocation from root to shoot is avoided by the AM fungi through the rhizofiltration mechanism.

\section{ACKNOWLEDGMENT}

We acknowledge the GOI-DST for providing the GC-MS and HPLC facility at TNAU, Coimbatore.

\section{REFERENCES}

Ade-Ademilua, O.E. and D.A. Obalola, 2008. The effect of cement dust pollution on celosia argentea (Lagos Spinach) plant. J. Environ. Sci. Technol., 1: 47-55.

Ahonen-Jonnarth, U., P.A.W. Vanhees, U.S.L. Lundstrom and R.D. Finlay, 2000. Organic acids produced by mycorrhizal Pinus sylvestis exposed to elevated aluminium and heavy metal concentrations. New Phytol., 146: 557-567. 
Alverez, M.E., 2000. Salicylic acid in the machinery of hypersensitive cell death and disease resistance. Plant Mol. Biol., 44: 429-442.

Bishnoi, N.R., A. Dua, V.K. Gupta and S.K. Sawhney, 1993. Effect of chromium on seed germination seedling growth and yield of peas. Agric. Ecosyst. Environ., 47: 47-57.

Bonet, A., C. Poschenrieder and J. Barcelo, 1991. Chromium III ion interaction in $\mathrm{Fe}$ deficient and $\mathrm{Fe}$ sufficient bean plants. I. Growth and Nutrient content. J. Plant Nutr., 14: 403-414.

Boominathan, R. and P.M. Doran, 2003. Organic acid complexation, heavy metal distribution and the effect of ATPase inhibition in hairy roots of hyperaccumulator plant species. J. Biotechnol., 101: 131-146.

Caltado, D.A., K.M. Mcfadden, R. Thomas and R.E. Wilddung, 1988. Organic constituent and complexation of nickel (II), Cadmium (II) and Plutonium (VI) in soybean xylem exudates. Plant Physiol., 86: 734-739.

Chaffai, R., A. Tekitek and E. El-Ferjani, 2006. A comparative study on the organic acid content and exudation in maize (Zea mays L.) seedlings under conditions of copper and cadmium stress. Asian J. Plant Sci., 5: 598-606.

Clemens, S., 2001. Molecular mechanisms of plant metal tolerance and homeostasis. Planta, 212: 475-486.

Clijsters, H. and F. Assche, 1985. Inhibition of photosynthesis by heavy metals. Photosynth. Res., 7: $31-40$.

Dat, J.F., H. Lopez-Delgado, C.H. Foyer and I.M. Scott, 1998. Parallel changes in $\mathrm{H}_{2} \mathrm{O}_{2}$ and catalase during thermo tolerance induced by salicylic acid or heat acclimation in mustard seedlings. Plant Physiol., 116: 1351-1357.

Davis, F.T., J.D. Puryear, R.J. Newton, J.N. Egilla and J.A.S. Grossi, 2001. Mycorrhizal fungi enhances accumulation and tolerance of chromium in sunflower (Helianthus annus). J. Plant Physiol., 158: 777-786.

Delhaize, E. and P.R. Ryan, 1995. Aluminum toxicity and tolerance in plants. Plant Physiol., 107: 315-321.

Dixit, V., V. Pandey and R. Shyam, 2002. Chromium ions inactivate electron transport and enhance superoxide generation in vivo in pea (pisum sativaum L. cv: Azad) root mitochondria. Plant Cell Environ., 25: 687-693.

Doss, D.D. and D.J. Bagayaraj, 1990. Anatomical observations on roots of finger millet colonized by VA mycorrhiza. Curr. Sci., 59: 423-424.
Einicker-Lamas, M., M.J. Soares, M.S. Soares and M.M. Olivera, 1996. Effects of cadmium on Euglena gracilis membrane lipids. Brazil. J. Med. Biol. Res., 29: $941-948$.

Farago, M.E. and W.A. Mullen, 1979. Plants which accumulate metals, IV. A possible copper-proline complex from the roots of Armeria maritima. Inorganic Chimica Acta, 32: 93-94.

Girotti, A.W., 2001. Photosensitized oxidation of membrane lipids: Reaction pathways, cytotoxic effects and cytoprotective mechanisms. J. Photochem. Photobiol., 63: 103-113.

Harmens, H., P.L.M. Koevnets, J.A.C. Verkleij and W.H.O. Ernst, 1993. The role of low molecular weight organic acids in the mechanism of increased zinc tolerance in Silene vulgaris. New Phytol., 126: 615-621.

James, B.R. and R.J. Barlett, 1983. Behavior of chromium in soils VI. Interactions between oxidation-reduction and organic complexation. J. Environ. Qual., 12: 173-176.

Janda, T., G. Szalai, I. Tari and E. Paldi, 1999. Hydroponic treatment with salicylic acid decreases the effects of chilling injury in maize (Zea mays L.) plants. Planta, 208: 175-180.

Jones, D.L. and P.R. Darrah, 1994. Influx and efflux of organic acids across the root soil interface of Zea mays $\mathrm{L}$. and its implications in rhizosphere $\mathrm{C}$ flow and mineral nutrition. Plant Soil, 158: 183-192.

Landeweert, R., E. Hoffland, R.D. Finlay, T.W. Kuyper and N. van Breemen, 2001. Linking plants to rocks: Ectomycorrhizal fungi mobilize nutrients from minerals. Trends Ecol. Evolution, 16: 248-254.

Lee, M. and M.H. Gaskins, 1982. Increased root exudation of ${ }^{14} \mathrm{C}$ compounds by sorghum seedlings inoculated with nitrogen fixing bacteria. Plant Soil, 69: 391-399.

Matewally, A., I. Finkemeir, M. Georgi and D.K.J. Dietz, 2003. Salicylic acid alleviates cadmium toxicity in barley seedlings. Plant Physiol., 132: 272-281.

Mathys, W., 1977. The role of malate, oxalate and mustard oil glucosides in the evolution of zinc resistance in herbage plants. Physiol. Plant., 40: 130-136.

Matile, P.H. and A. Wiemken, 1976. Interactions Between Cytoplasm and Vacuole. In: Transport in Plants III: Intracellular Interactions and Transport Processes, Encyclopedia of Plant Physiology, Stocking, C.R. and U. Heber (Ed.). Springer-Verlag, Berlin, pp: $255-287$.

Mazen, A.M.A., 2004. Accumulation of four metals in tissues of Corchorus olitorius and possible mechanisms of their tolerance. Biol. Plant, 48: $267-272$. 
Meharg, A., 2003. The mechanistic basis of interactions between mycorrhizal associations and toxic metal cations. Mycol. Res., 107: 1253-1265.

Mishra, S. and R.S. Dubey, 2006. Heavy metal uptake and detoxification mechanisms in plants. Int. J. Agric. Res., 1: 122-141.

Noctor, G. and C.H. Foyer, 1998. Ascorbate and glutathione: Keeping active oxygen under control. Annu. Rev. Plant Physiol. Mol. Biol., 49: 249-279.

Ozturk, L., S. Karanlik, F. Zkutlu, I. Aakmak and L.V. Kochian, 2003. Shoot biomass and zinc/cadmium uptake for hyper accumulator and non-accumulator Thlaspi species in response to growth on a zinc-deficient calcareous soil. Plant Sci., 164: 1095-1101.

Panda, S.K., 2002. The Biology of Oxidative Stress in Green Cells: A Review. In: Advances in Stress Physiology of Plants, Panda, S.K. (Ed.). Scientific Publishers, Jhodpur, India, pp: 1-3.

Rea, P.A., Z.S. Li, Y.P. Lu and Y.M. Drozdowicz, 1998. From vacuolar GS-X pumps to multispecific $\mathrm{ABC}$ transporters. Annu. Rev. Plant Physiol. Plant Mol. Biol., 49: 727-760.

Reilly, C., 1972. Amino acids and amino acid copper complexes in water soluble extracts of copper tolerant and non tolerance Becium homblei. Z. Pflanzenphysiol., 66: 294-296.

Rice-Evans, C.A., N.J. Miller and G. Paganga, 1996. Structure-antioxidant activity relationships of flavonoids and phenolic acids. Free Radic. Biol. Med., 20: 933-956.

Rocchetta, I., L.B. Ruiz, G. Magaz and V. Conforti, 2003. Effects of hexavalent chromium in two strains of Euglena gracilis. Bull. Environ. Contam. Toxicol., 70: 1045-1051.

Salehi, A. and M. Tabari, 2008. Accumulation of $\mathrm{Zn}, \mathrm{Cu}$, $\mathrm{Ni}$ and $\mathrm{Pb}$ in soil and leaf of Pinus eldarica medw. Following irrigation with municipal effluent. Res. J. Environ. Sci., 2: 291-297.

Schat, H., S.S. Sharma and R. Vooijs, 1997. Heavy metal-induced accumulation of free proline in metal-tolerant and a non-tolerant ecotype of Silene vulgaris. Physiol. Planta., 101: 477-482.
Seel, W.E., G.A.F. Hendry and L.A. Lee, 1992. The combined effect of desiccation and irradiance on mosses from xeric and hydric habitats. J. Expl. Bot., 43: 1023-1030.

Seyyednejad, S.M., M. Niknejad and H. Koochak, 2011. A review of some different effects of air pollution on plants. Res. J. Environ. Sci., 10: 302-309.

Shahandeh, H. and L.R. Hossner, 2000. Enhancement of $\mathrm{Cr}$ (III) phytoaccumulation. Int. J. Phytoremed., 2: 269-286.

Smirnoff, N. and Q.J. Cumbes, 1989. Hydroxyl radical scavenging activity of compatible solutes. Phytochemistry, 28: 1057-1060.

Srivastava, S., S. Prakash and M.M. Srivastava, 1999. Studies on mobilization of chromium with reference to its plant availability-Role of organic acids. BioMetals, 12: 201-207.

Turgut, C., M.K. Pepe and T.J. Cutright, 2004. The effect of EDTA and citric acid on phytoremediation of $\mathrm{Cd}$, $\mathrm{Cr}$ and $\mathrm{Ni}$ from soil using Helianthus annuus. Environ. Pollution, 131: 147-154.

Vazqyez, M.D., J. Barcelo, C.H. Poschenrieder, J. Madico, P. Hatton, A.J.M. Baker and G.H. Cope, 1992. Localization of zinc and cadmium in Thlaspi caerulescens a metallohytte that can hyper accumulate both metals. J. Plant Physiol., 140: $350-355$.

Whipps, J.M., 1990. Carbon Economy. In: The Rhizosphere, Lynch, J.M. (Ed.). John Wiley, Chichester, pp: 59-97.

Williams, C. and A. Nascimento, 2006. Organic acids effects on desorption of heavy metals from a contaminated soil. Sci. Agric., 63: 276-280.

Zancani, M. and G. Nagy, 2000. Phenol-dependent $\mathrm{H}_{2} \mathrm{O}_{2}$ breakdown by soybean root plasma membranebound peroxidase is regulated by ascorbate and thiols. J. Plant Physiol., 156: 295-299. 